\title{
Histogenesis of thymus in human foetuses of different gestational ages - A Pilot Study
}

\author{
${ }^{1}$ Srinivasa Rao Y, ${ }^{2}$ SwayamJothi S, ${ }^{3}$ Saratha Kathiresan \\ ${ }^{1}$ Asst professor, Dept of Anatomy, GIMSR, Visakhapatnam, AP, India \\ ${ }^{2}$ Professor \& HOD, Dept of Anatomy, SSSMCRI, Chennai \\ ${ }^{3}$ Retired Director of Anatomy, MMC, Chennai
}

\begin{abstract}
Thymus is a primary lymphoid organ playing an important role in the development of immune system by generation of " $T$ - cells". It is a bilobed and encapsulated organ consisting of two pyramidal lobes. Understanding age related changes in the macroscopic and microscopic appearance of the thymus is important in the evaluation of patients with diseases of thymus which are presented as a variety of immune system disorder and hence this study. The present work is the result of pilot study of 15 human foetal thymus obtained from the museum of department of Anatomy, GIMSR, Visakhapatnam. Age of the fetuses ranged from 19-40 weeks Visakhapatnam. The lobulation and cortico-medullary distinction was observed at 19 weeks gestation. Branching blood vessels at cotico-medullary junction and thicker capsule with wider inter lobular septae and Hassall's corpuscles were observed in thymic glands of $21^{s t}$ weeks old fetuses. Hassall's corpuscles which are peculiar nest like bodies with a central mass consisting of more granular cells made their appearance in $26^{\text {th }}$ week of gestation. Cortex with dense populated lymphocytes is observed. Medulla possessed Hassall's corpuscles of increasing maturity with few lymphocytes in $26^{\text {th }}$ week of gestation. Similar findings were observed in $30^{\text {th }}$ weeks of gestation. The gland during $34^{\text {th }}$ week of gestation showed internal architecture of lobulation, septation and cortical demarcation with increased density of lymphocytes and medulla
\end{abstract}

Keywords: Thymus, Cortex, Medulla, Hassall's Corpuscles.

\section{Introduction}

The name thymus comes from the Latin derivation of the Greek thymos, meaning "warty excrescence" due to its resemblance to the flowers of the thyme plant. The earliest known reference to the thymus is attributed to Rufus of Ephesus circa 100 A.D, a Greek anatomist renowned for his investigations of the heart and eye. Rufus attributed the discovery of the thymus to the Egyptians. Hassall AH and Vanarsdale H (1846) used recent improvements in compound microscope lens quality to study the thymus more thoroughly. Hassall's famous corpuscles were thus named. They also described differences between the thymus and other lymphoid tissues. Thymus is a primary lymphoid organ playing an important role in the development of immune system by generation of "T- cells". It is a bilobed and encapsulated organ consisting of two pyramidal lobes. It is located in the mediastinum behind the sternum and in front of the pericardium and great vessels of the heart in the adult. Embryologically, the thymus is derived from all 3 germinal layers and arises primarily from the third pharyngeal pouch.Thymus development commences early during fetal life, with the most critical period of growth thought to occur between 7 and 14 weeks of gestation. The thymic organogenesis begins at the third branchial pouch and the first lymphocytes appear in the thymus during ninth week of gestation[Jeppensen et al, 2009]. The paired epithelial primordia of thymus develop from the ventral part of 3rd pharyngeal pouch along with inferior parathyroid primordia in the region of superior neck in early fetal life. It progressively descends caudally with the descent of heart and aortic sac to reach final destination in the superior mediastinum.

\section{Aim Of The Study}

Understanding age related changes in the macroscopic and microscopic appearance of the thymus is important in the evaluation of patients with diseases of thymus which are presented as a variety of immune system disorder.

\section{Materials And Methods}

The present work is the result of pilot study of 15 human foetal thymus obtained from the museum of department of Anatomy, GIMSR, Visakhapatnam. Age of the fetuses ranged from 19-40 weeks Visakhapatnam. The age of foetus is judged by CR length.

The preserved fetuses in the jars of the museum were taken out, a window shaped incision was made in the region of superior mediastinum and thymus was observed and removed.

The human fetuses were categorized into groups. 
$\begin{array}{ll}\checkmark & 1^{\text {rd }} \text { group }-19 \text { to } 25 \text { weeks } \\ \checkmark & 2^{\text {nd }} \text { group }-26 \text { to } 32 \text { weeks } \\ \checkmark & 3^{\text {rd }} \text { group }-33 \text { to } 40 \text { weeks }\end{array}$

The thymus was subjected to histological studies \& observed under H\&E stain..

\section{Observations}

The lobulation and cortico-medullary distinction was observed at 19 wks gestation.

Each lobule had a peripheral dark zone called cortex and a light central zone called medulla.Medulla was recognized by its light stain containing WBC and epithelial cells (Fig.1). Branching blood vessels at coticomedullary junction and thicker capsule with wider inter lobular septae and Hassall's corpuscles were observed in thymic glands of $21^{\text {st }}$ weeks old fetuses (Fig.2).

Hassall's corpuscles which are peculiar nest like bodies with a central mass consisting of more granular cells made their appearance in $26^{\text {th }}$ week of gestation (Fig.3). Cortex with dense populated lymphocytes is observed. Medulla possessed Hassall's corpuscles of increasing maturity with few lymphocytes (Fig.4) in $26^{\text {th }}$ week of gestation. Similar findings were observed in $30^{\text {th }}$ weeks of gestation (Fig.5).

The gland during $34^{\text {th }}$ week of gestation showed internal architecture of lobulation, septation and cortical demarcation with increased density of lymphocytes and medulla (Fig.6).

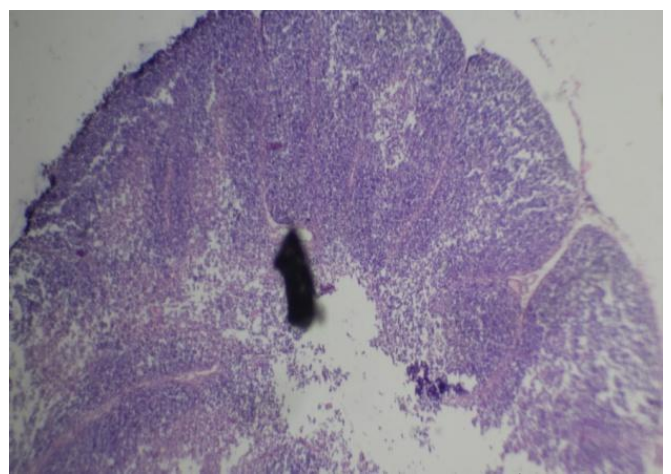

Fig.1- Lobulation $\&$ cortico-medullary distinction of $19^{\text {th }}$ week of gestation $(4 \mathrm{X} \mathrm{H} \& \mathrm{E})$

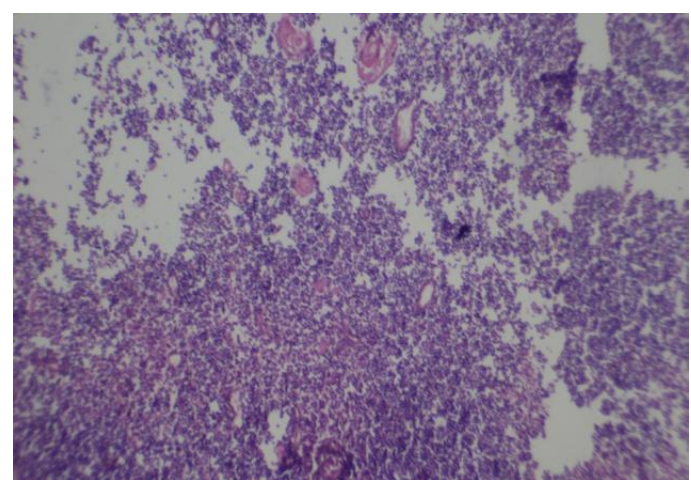

Fig.2 - Branching blood vessels at cotico-medullary junction of 21 week gestation(10X H\&E)

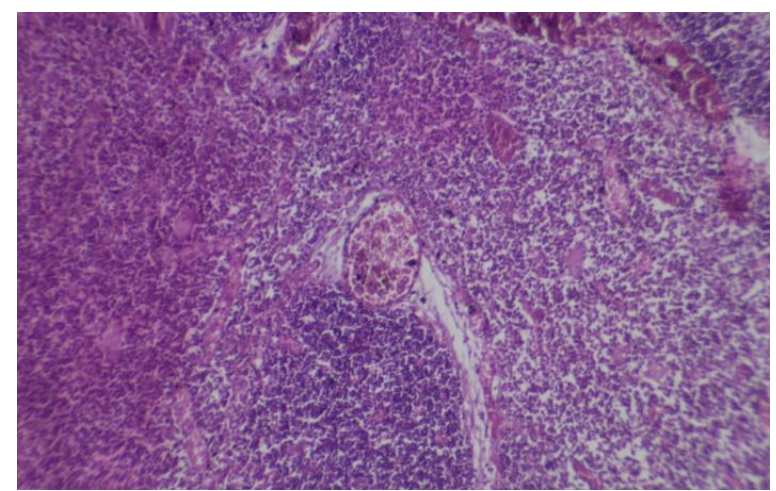

Fig.3 - Hassall's corpuscles with a central mass consisting of more granular cells made their appearance in $26^{\text {th }}$ week of gestation (40X H\&E) 


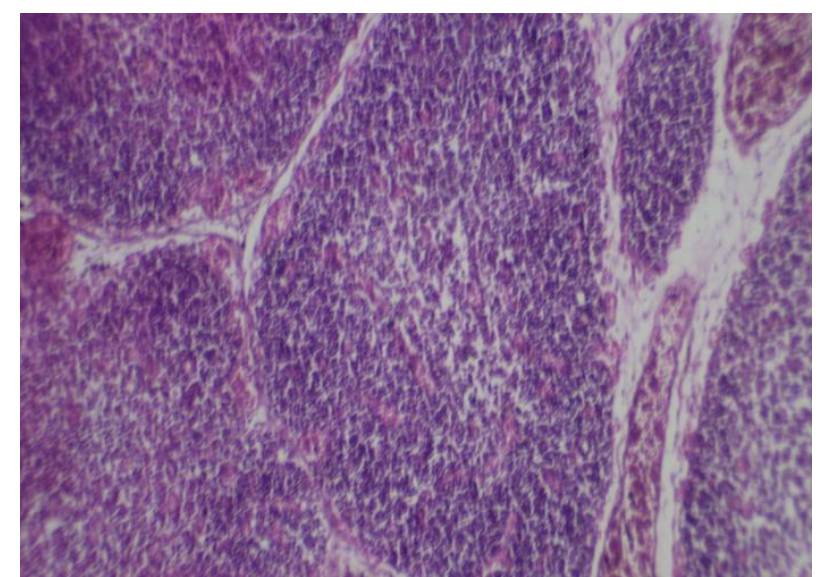

Fig.4 - Cortex with dense populated lymphocytes in $26^{\text {th }}$ week of gestation.(10X H\&E)

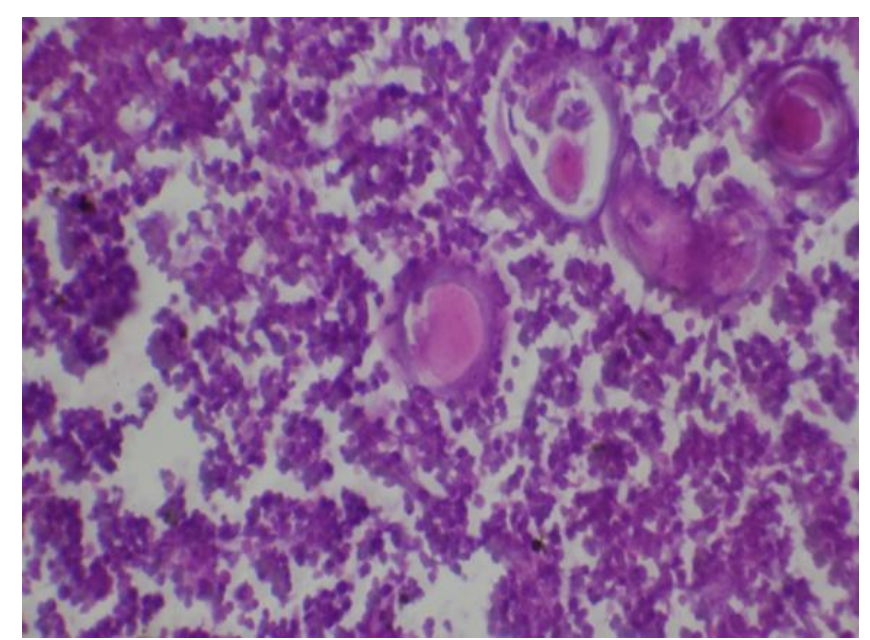

Fig.5 - Medulla possessed Hassall's corpuscles ofincreasing maturity with few lymphocytes in $30^{\text {th }}$ weeks of gestation (40X H\&E)

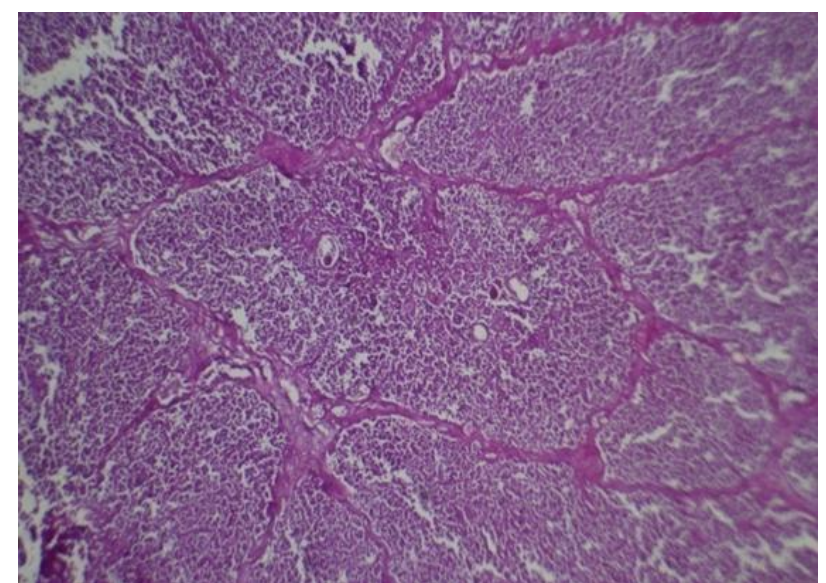

Fig.6- showing density of lymphocytes and septae of foetal thymus in $34^{\text {th }}$ week of gestation (4X H\&E)

\section{Discussion}

Thymus gland finds it's pathway of descent from 3rd branchial arch. During the 6th week of gestation, epithelial out pouching from the ventral aspect of 3rd pharyngeal pouch arch starts to develop and move caudally forming what is known as thymo pharyngeal duct. Inferior parathyroid also develops from 3rd pharyngeal pouch. There was a very minor and rudimentary portion of thymic tissue which develops from ventral aspect of 4 th pouch.

Cortex-medulla differentiation and early stage of formation of Hassall's corpuscles were observed at 14 -16 weeks gestation and Varga etal (2011), reported cortico-medullary differentiation at 13th week. The study in 
west Bengal region of India by Ajita etal (2006), who reported cortico-medullary differentiation at 9-11 weeks and Varga et al, (2011), reported noticeably wide interlobular septa at 14-16 weeks. In the present study, lobulation and cortico-medullary differentiation of the thymus was observed at $19^{\text {th }}$ week of gestation. Good number of relatively large Hassall's corpuscles, branching blood vessels at cotico-medullary junction and thicker capsule with wider inter lobular septae were observed inthymic glands of 20-24 weeks old fetuses by Bodey, Siegel et al (2000). However, in the present study, these were observed at 21 week of gestation.

The first developing Hassall's corpuscle was reported at $13^{\text {th }}$ week by Varga et al. and $15^{\text {th }}$ week by Ajita et al, (2006). They are seen as epithelial pearls of different sizes and shapes as reported by Saradha Kathiresan (2007). In the literature there are varying reports on the time of appearance of Hassall's corpuscle as early as $8^{\text {th }}$ week ( Fawcett, 1994), 9th week (Gilhus et al, 1985 ), at $10^{\text {th }}$ week (Williams et al, 1995), at $11^{\text {th }}$ week (Ghali et al, 1980), between $15^{\text {th }}$ and $16^{\text {th }}$ week (Lobach D F, and Haynes B F, 1987). Liberti et al, and Varga et al, reported these findings at 16-18 weeks. In the present study Hassall's corpuscles were observed at $19^{\text {th }}$ week of gestation. Liberti et al, (1994) reported that the mean areas of the Hassall's Corpuscles increased with the foetal age, with the greatest observable difference between $20^{\text {th }}$ to $23^{\text {rd }}$ weeks. According to Valdes (1957), Shah et al, (2005), Hassall's Corpuscles increased in number and size during $17^{\text {th }}$ to $24^{\text {th }}$ week. Between $26^{\text {th }}$ weeks to full term the hyalinization and keratinization of Hassall's corpuscles and "Starry sky appearance" at cortico-medullary junction. Similar findings were observed in the present study.

\section{Conclusion}

This being a pilot study conclusion could not be derived at his level.

\section{References}

[1] Ajita RK, Naranbabu Singh T H, Ibochouba Singh Y, Chandramani Singh L: An insight into the structure of the thymus in humanfoetus - a histological approach. J. Anat. Soc. India, 2006; 55(1); pp 45-49.

[2] Bodey B, Kayser H E: Development of Hassall's bodies of the thymus in humans and othervertebrates especially mammals (1997) under physiological and pathological conditions:immuno-cytochemical, electron microscopic and in vitro observations. In vivo, 1997; 11 (1):61-85.

[3] Bodey B, Siegel S E, Kaiser H E.: Novel insights into the function of the thymic Hassall's bodies. In vivo, 2000 ; 14 (3): pp 407-418.

[4] Fawcett D W: A Text Book of Histology in Thymus 1994; 12th Edn, Chapman and Hall: New York. pp. $432-444$.

[5] Ghali WM, Abedl -Rahman S, Nagib M and Mahran ZY (1980). Intrinsic innervation and vasculature of pre and post-natal human thymus. ActaAnatomica $\mathbf{1 0 8} 115-123$

[6] Gilhus N E, Matre R and Tonder O.: Hassall's Corpuscles in the thymus of foetuses, infants and children: immunological and histochemical aspects. Thymus, 1985; 7 (2): 123-135.

[7] Hassall AH and Vanarsdale H (1846).Illustrations of the microscopic anatomy of the human body in health and disease. In: Hassal AH, eds. Microscopic Anatomy of the Human Body in Health and Disease (London, England) Wood 1-79.

[8] Hassall AH (1849). The microscopic anatomy of the human body in health and disease, Plate LXI, London.foetus-a histological approach. Journal of Anatomical Society of India, 2006, vol. 55, n. 1, p. 45-49.

[9] Jeppesen DL, Hasselbalch H, Nielsen SD, Sorensen TU, Ersboll AK, Valerius NH, et al. (2003). Thymic size in preterm neonates: a sonographic study. Acta Paediatr. 92: 817-822.

[10] Liberti EA, Fagundes T P, Perito M A, Matson E, Konig Junior B: On the size of Hassall's corpuscles in human fetuses. Bull Assoc(Anatomy), 1994; 78 (242): pp15-18.

[11] Lobach D F, and Haynes B F: Ontogeny of the human thymus during foetal development. J Clin. Immunol, 1987 ; 7 : 81-97.

[12] SarathaKathiresan: The human foetal thymus published by the author in 2007; pp. $113-127$.

[13] Shah P: Mediastinum Thymus in Gray's Text book of Anatomy. Elsevier Churchill Livingstone; 39th ed. 2005, pp. 980- 984.

[14] Steinman GG, Klaus B, Mueller-Hermelink HK (1985) The involution of the ageing human thymic epithelium is independent of puberty. A morphometric study. Scand J Immunol 1985: 22: 563-575.

[15] Valdes - Dapena M. A.: Thymus. An atlas of fetal and neonatal histology, 1957.

[16] Varga I, Pospisilova V, Jablonska-Mestanova, Galfiova P, Polak S. The thymus: Picture review of human thymus prenatal development. BratisiLekListy, 2011; 112 (7): pp 368-376.

[17] Williams P L, Bannister L H, Berry M M, Collins P, Dyson M, Dussek J E, Ferguson M W:Haemolymphoid system In: Gray’s Anatomy. 38th Edition, 1995; ELBS with ChurchillLivingstone, Edinburgh, London. pp. 1423-1431. 